\title{
Review:
}

\section{Comparison of the technologies of the Japanese Shinkansen and Chinese High-speed Railways}

\author{
Satoru SONE \\ (Kogakuin University, Tokyo 113-8677, Japan) \\ E-mail: sonesatoru@gmail.com \\ Received July 30, 2015; Revision accepted Aug. 31, 2015; Crosschecked Sept. 9, 2015
}

\begin{abstract}
After describing Japanese slow but steady progress and Chinese very rapid progress of high-speed railways, comparison and analysis of ways of development and those of specific components are discussed. By adding descriptions of European developments which are much different to Japanese, comparisons are made between Japanese and Chinese strong and weak points in order to contribute to the improvement of worldwide rail passengers' transport including inferior aspect of both countries systems.
\end{abstract}

Key words: High-speed railway, Medium speed railway, Suburban railway, Distributed traction, Concentrated traction, MT ratio, Power feeding system, Current collection, Electromagnetic compatibility (EMC) problems, Safety and reliability, Coordination

doi: $10.1631 /$ jzus.A1500220

Document code: A

CLC number: U2

\section{Brief history of Japanese and Chinese High-speed Railways}

The world's first high-speed railway (HSR), the Japanese Tokaido Shinkansen was inaugurated in 1964. This obviously means naturally that Japan has the longest experience of HSR but also by far the greatest experience of problems on HSR because Japan's traffic volume was, and still is, much denser than any other European countries, that followed Japan in the field of HSR (Smith, 2014; Takai, 2015).

On the other hand China started internal discussion of an increase in train speed as late as the 1990s and the first real attempt took place in 1997 at a maximum speed of $140 \mathrm{~km} / \mathrm{h}$, whilst Japan was beginning $300 \mathrm{~km} / \mathrm{h}$ operation on the Sanyo Shinkansen (Ehara, 2015). Up to 2003 research and development (R\&D) of this field in China was based on China's own knowledge and skill but was revealed to be too slow to catch up with the national fast-growing

(D) ORCID: Satoru SONE, http://orcid.org/0000-0002-8037-2925 (C) Zhejiang University and Springer-Verlag Berlin Heidelberg 2015 economy, so the government decided to change its own method of realising HSR based on its own internal development to the introduction of technologies from the developed countries. Thus, based on mainly Japanese and German technologies in addition to China's strategic plan of introduction and abundant resources, the first substantial increase in train speed took place in 2007, as the sixth increase in train speed (countries with major technical and manufacturing centres for the origins of CRH1, CRH2, CRH5, and CRH3 are Germany (not Canada), Japan, Italy (not France), and Germany, respectively). At this time-point many railway people around the world paid attention suddenly with much surprise; because the route length of HS tracks exceeded 6000 singletrack $\mathrm{km}$, which was longer than those of any other countries, including Japan and France.

2015 , only eight years after 2007, see Table 1 of route length of more than $16000 \mathrm{~km}$ in China, which exceeds the total length of all other HSRs put together with the second to fifth being Spain $(3400 \mathrm{~km})$, Japan $(2800 \mathrm{~km})$, France $(2100 \mathrm{~km})$, and Germany $(1800 \mathrm{~km})$, respectively. 


\section{Comparison of HSRs in Japan and China by basic transportation figures}

To compare the figures and to understand the differences some major data are shown in Table 2.

\section{Comparison of technological achieve- ments of HSRs in Japan and in China}

\subsection{Outline}

\subsubsection{Original technologies of Japan and of China}

It can be thought that all or almost all technologies of HSR are of Japanese origin because Japan was the pioneer in the world for HSRs, but actually this was not the case. When Japan decided to construct a Shinkansen between Tokyo and Osaka, the conventional Tokaido line, which was and still is a double tracked electrified railway with comparatively short quadruple track sections near Tokyo and near Osaka, was approaching its limit of transportation capacity and the quick addition of two more tracks was an absolutely necessary requirement. The majority of the then Japanese National Railways (JNR) managers intended to add a double track route alongside the conventional narrow gauge tracks. To add two more tracks on the same route was thought extremely difficult in the already densely populated area in a short period of five targeted years, so an alternative idea to construct a separate route with necessary interchanges was the most viable. But there were a few people who had strongly wanted to improve the JNR by changing the narrow gauge to standard gauge since the end of 19th century, less than 30 years after the first railway opened in Japan. The then president of JNR, Shinji SOGO (十河 信二) was one of them, but all other influential JNR people were not. Shinji SOGO and Hideo SHIMA (島 秀雄) who had been retired after severe accident on the JNR and recalled by SOGO as Chief Engineer, together proposed strongly to add a standard gauge new double track line instead of a quadrupled conventional line. SOGO and SHIMA were able to narrowly persuade the rest of JNR headquarters and the Shinkansen was therefore successfully initiated. In this situation, the Shinkansen had to realise enough traffic capacity for both expanding passenger and freight traffic together with the conventional line with enough availability and by the

Table 1 Basic transportation figures of high-speed railways in Japan and in China ${ }^{\#}$

\begin{tabular}{|c|c|c|c|c|c|c|}
\hline \multirow{2}{*}{$\begin{array}{l}\text { Fiscal } \\
\text { (year) }\end{array}$} & \multicolumn{3}{|c|}{ Japan } & \multicolumn{3}{|c|}{ China $^{*}$} \\
\hline & $\begin{array}{l}\text { Route } \\
(\mathrm{km})\end{array}$ & $\begin{array}{c}\text { Passengers } \\
\text { carried }\left(\times 10^{4}\right)\end{array}$ & $\begin{array}{c}\text { Transported } \\
\text { passenger-km }\left(\times 10^{8}\right)\end{array}$ & $\begin{array}{l}\text { Route } \\
(\mathrm{km})\end{array}$ & $\begin{array}{c}\text { Passengers } \\
\text { carried }\left(\times 10^{4}\right)\end{array}$ & $\begin{array}{c}\text { Transported } \\
\text { passenger-km }\left(\times 10^{8}\right)\end{array}$ \\
\hline 1965 & 553 & 3097 & 107 & 0 & & \\
\hline 1975 & 1177 & 15722 & 278 & 0 & & \\
\hline 1985 & 2012 & 17983 & 554 & 0 & & \\
\hline 1995 & 2037 & 27590 & 708 & 0 & & \\
\hline 2005 & 2387 & 30140 & 779 & 0 & & \\
\hline 2008 & 2387 & 31024 & 817 & 1077 & 734 & 16 \\
\hline 2010 & 2620 & 32444 & 769 & 5133 & 13323 & 463 \\
\hline 2012 & 2620 & 32200 & 860 & 9356 & 38815 & 1446 \\
\hline 2014 & 2848 & 33969 & $910^{* *}$ & 16456 & 70378 & 2815 \\
\hline
\end{tabular}

\# The figure is based on commercial route length, which is sometimes up to $15 \%$ longer than the actual length both in China and in Japan for various reasons, and Japan's figure of 2848 commercial-km corresponds to an actual length of $2765 \mathrm{~km}$; ${ }^{*}$ Data are provided by Prof. Zhong-ping YANG from Beijing Jiaotong University, China; ${ }^{* *}$ Not yet officially disclosed and estimated by the author

Table 2 Differences in scale of China vs. Japan to understand HSRs

\begin{tabular}{ccccccc}
\hline \multicolumn{7}{c}{ Expressed by Chinese figure/Japanese figure of each item } \\
\hline Land area & Population & $\begin{array}{c}\text { Route } \\
(\mathrm{km})\end{array}$ & $\begin{array}{c}\text { Passengers } \\
\text { carried }\end{array}$ & $\begin{array}{c}\text { Transported } \\
\text { passenger-km }\end{array}$ & $\begin{array}{c}\text { Number of } \\
\text { Vehicles }\end{array}$ & $\begin{array}{c}\text { Maximum number of } \\
\text { trains per day }^{*}\end{array}$ \\
\hline 25 & 11 & 5.8 & 2.1 & 3.1 & $3.3(15536 / 4755)$ & 1.0 (average 330) \\
\hline
\end{tabular}

* Comparison with the Tokaido Shinkansen (Tokyo-Osaka) and Beijing-Shanghai HSR 
targeted opening date. Thus, all construction and trains together with the operating systems design were very conservative without any important failure allowed. Conservative design means not too innovative, rather heavy cars, less speedy movement, and a tendency to have an excess margin in vehicle safety and a small potential to increase further the train speed in future track design.

3.1.2 Original design of Japan's cars: development of light-weight bogies with stable operation at high speed (Sone, 2014)

The Shinkansen's car was based on a very innovative super express (SE) trainset of the Odakyu Electric Railway (OER), which established a world speed record on a $1067 \mathrm{~mm}$ gauge railway of $145 \mathrm{~km} / \mathrm{h}$ in 1957 and a tare weight of $147 \mathrm{t}$ with $108 \mathrm{~m}$ length. The Shinkansen's Series 0 cars were comparatively heavy with an average $56 \mathrm{t}$ tare weight and each was $25 \mathrm{~m}$ long. To avoid a further increase in mass, a wheel base of $2.5 \mathrm{~m}$ and a wheel diameter of $0.91 \mathrm{~m}$ was chosen and proven to have enough stability margin to run up to $210 \mathrm{~km} / \mathrm{h}$. JNR intended to reduce each car by $4 \mathrm{t}$, to realise a maximum axle load of $15 \mathrm{t}$, but failed mainly because of the mass of the traction equipment with enough margin. This meant an axle load of $16 \mathrm{t}$ was narrowly met including the fully seated passengers.

3.1.3 Original design of Japan's cars: distributed traction system with all axles motored

Based on the then Japanese Private Railways (JPR) standard design of high performance electric multiple units (EMUs), the traction system of paired motor cars with eight traction motors controlled by a traction controller was a natural and unique solution and never a result of the optimised design of a number of cars, motored and non-motored, i.e., trailer cars. After Japan's success with the HSR, Britain and France followed in 1976 and in 1981, respectively, but with concentrated traction systems of different types. Until the 1990s, when AC motor traction ${ }^{1}$ was available, concentrated traction systems were thought by many railway engineers other than Japanese to be superior to distributed traction with less maintenance

\footnotetext{
${ }^{1}$ Excluding widely used $\mathrm{AC}$ commutator motors used on $16.7 \mathrm{~Hz}$ electrified lines, which are similar to DC motors
}

of traction motors and more maintenance of non-motored axles' braking system. But in $1992 \mathrm{Ja}$ pan's Shinkansen succeeded in introducing the world's first high-speed EMU with AC regenerative braking, as the Shinkansen's Series 300 (Fig. 1). In R\&D works for this innovative trainset (the author was one of the team), a very important discovery was revealed; a non-motored axle with a necessary brake has more mass (total and unsprung mass) with more heat and more maintenance works required than a motored axle mainly because of the theoretical results of the braking system requiring kinetic energy to heat energy conversion. Thus, in Japan the next Series 500 was changed from $10 \mathrm{M} 6 \mathrm{~T}$ formation to $16 \mathrm{M}(0 \mathrm{~T})$, mainly to reduce the unsprung and total mass. This important knowledge was presented in 1994 at the World Congress on Railway Research (WCRR) in Paris by the author (Sone, 1994).

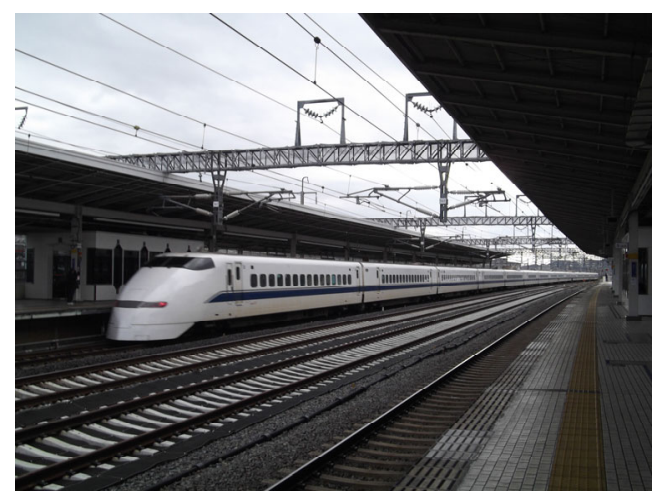

Fig. 1 Series 300 of Central Japan Railways; the world first high-speed trainset adopting regenerative braking

\subsubsection{Chinese design concept}

When China decided in 2003 to introduce HS trainsets from developed countries, it excluded concentrated traction systems such as the French TGV (Train à Grande Vitesse), German ICE-1 (InterCity Express), and Italian ETR500; this sound and clever decision was supposed to be based on the above-mentioned Japanese result as well as China's own experience of difficulties in the R\&D of China Star (中華之星), with concentrated traction, against Changbaishan (長白山), with distributed traction trainsets. All of the introduced CRH1, CRH2, CRH5, and $\mathrm{CRH} 3$ have distributed traction systems but there are two different types; CRH2's with driving trailers and the rest of CRH1, CRH5, and CRH3's all of 
which are of European origin, with driving motors (Zhang, 2009a). This difference is, from Japanese experience, very important from the following two viewpoints: from the electromagnetic compatibility (EMC) point of view, a driving motor whose front bogie has traction motors brings much more trouble to signalling circuits, and from the adhesion point of view as well. Wheels of the front bogie tend to slip and slide because they are still wet in rainy condition. On the contrary, a formation with driving trailers and intermediate motors does not require sophisticated adhesion control and if there is no brake applied at the front bogie, the wheels can be used as a reliable speed and position sensor because they do not slide at all (Fig. 2).

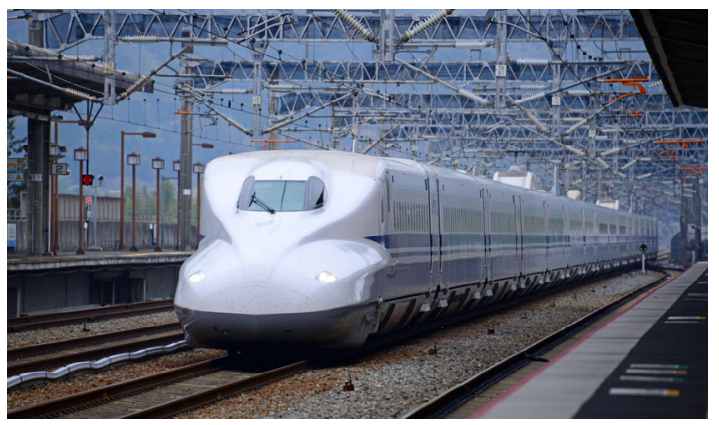

Fig. 2 Series N700 (14M2T) of Central Japan Railways; this can run at $270 \mathrm{~km} / \mathrm{h}$ at $2500 \mathrm{~m}$ radius sharp curve by body inclination control

Figs. 2, 4, and 5 were provided by Mr. Chun-xiao LUO from Editorial Office of Railway Knowledge, China

At present, Chinese designed HS trainsets, CRH380's, are of the above-mentioned two types; CRH380A and AL consist of driving trailers with all intermediate cars motored while the rest of CRH380B, $\mathrm{C}$, and $\mathrm{D}$ have driving motors and intermediate motors and trailers with the same numbers of motors and trailers: 4M4T or 8M8T (Yang, 2015). If Chinese railways want to standardise the traction systems, the author strongly proposes driving trailers with as many numbers of motors as are economically viable. Even if a sophisticated and high performance re-adhesion control is used, small slip and slide are inevitable under adverse conditions, meaning that the acquired speed and position have many errors. If CRH380AL's $14 \mathrm{M} 2 \mathrm{~T}$ formation is thought to provide too much margin and is too expensive compared with CRH380A's 6M2T formation using the same traction motors, the 12M4T formation may be the best solu- tion for construction costs, but still the running cost may be better for the $14 \mathrm{M} 2 \mathrm{~T}$ because of much better braking performance.

\subsection{Comparison of achievements of the HSR in Japan and in China relating to subsystems used}

\subsubsection{Power feeding system}

Among Japanese original technologies, one of which that has not yet been adopted in other countries is the quasi-continuous power feeding system using two consecutive catenary sections and wayside change-over switch (Ishikawa et al., 2015). The system's action is as follows (Fig. 3): suppose the train moves from $A$ to $C$ via $B$, the switch $D$ is kept closed until the whole train enters the section $\mathrm{B}$, when $\mathrm{D}$ is off and a very short time, typically $0.3 \mathrm{~s}$, after opening $\mathrm{D}$, switch $\mathrm{E}$ is closed. This system together with simple but superior current collection using two interconnected pantographs achieves nearly perfect current collection because of no interrupted acceleration and deceleration using a regenerative brake and stable electrical connection even when one pantograph loses mechanical contact (Study Group of High-speed Railways, 2003). At the moment the European system prohibits the use of a parallel connected two pantograph system to prevent short circuiting from two power sources in different phases. The change-over switch was improved from the original air blast type and then changed to a vacuum switch and now gradually to a semiconductor type.

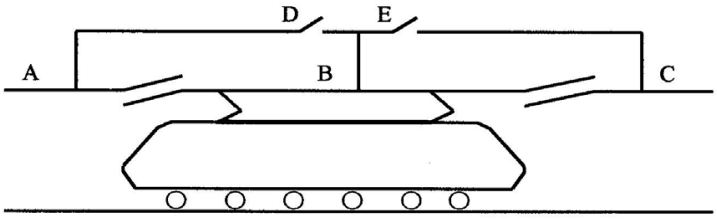

Fig. 3 Quasi-continuous power feeding system Before entering to $\mathrm{B}$, switch $\mathrm{D}$ is kept on, after the whole train with two interconnected pantographs comes into B, switch D turns off and about $300 \mathrm{~ms}$ after that switch $\mathrm{E}$ turns on. Interruption of $300 \mathrm{~ms}$ was necessary in the technology of 1960 s by various reasons when slow action contact switch is only available. The train can run through in either mode of acceleration, coasting or regenerative braking

China studied using a quasi-continuous power feeding system but has abandoned it for the moment. The reason was supposed to be easy acceptance of the European type trainset and changeover switches are 
still being improved from vacuum breaker type to semiconductor ones.

\subsubsection{Electromagnetic compatibility}

In Japan there are many special designs for avoiding EMC problems based on experienced difficulties. Contrary to the above-mentioned standard practice, Series N700 of 8 car formation in the Kyushu and the Sanyo Shinkansen are not 6M2T with driving trailers but $8 \mathrm{M} 0 \mathrm{~T}$ with driving motors to cope with restarting conditions after stopping on a steep gradient section of $35 \%$ with half the units cut-off (Fukunaga, 2015). To cope with EMC problems due to driving motors, traction motors and bogies are of slightly different designs for the front bogie, rear bogie of the front car and of intermediate cars both from an emission and immunity point of view. As far as adhesion is concerned, acceleration and deceleration forces of the front two bogies are squeezed while the rest, including the rearmost cars, produce full force.

\subsubsection{Phase balancing measures after introduction of} regenerative trains

The author should touch upon a practice and its changes in phase balancing measures relating to a single phase high power load from a three phase power grid. At the start of the Tokaido Shinkansen in 1964, three phase AC was converted to rectangular two phase AC using Scott connected transformers. One phase was fed to down tracks and the other to up tracks. Thus, on average on most occasions a better balance was established because average power was almost balanced between down and up trains. The situation was changed in two ways: in a change from a booster transformer (BT) feeding system to an auto-transformer (AT) system and the introduction of regenerative trains. A BT was used to pick up return current flowing in the running rails to a negative feeder located about the same height as the catenary wires so that induced electrical noise to nearby communication wires was cancelled. This was good for avoiding EMC but for current collection the BT section was a weak point where the terminal voltage of BT should be broken by leaving pantograph producing electrical arc every time a train passed across the BT section. To cope with this problem, the BT feeding system was changed to an AT feeding system and according to this the power balance to be expected was changed from between up trains and down trains to between up and down trains running on one side of a substation and those on the other side.

The other important change in the situation was the introduction of regenerative trains in 1992. The principle of three to two phase conversion by a traction transformer is that when the power sum of one of the two phases is equal to that of the other phase, the three phase side is balanced. Before the introduction of regenerative braking, the worst case is maximum power at one phase and zero at the other phase. In this worst case three phase to two phase conversion has no effect; the same as taking the total power from one of the three phases alone, but after the introduction of a regenerative brake the worst case is positive power on one side and negative power on the other side; in this case three to two phase conversion has a negative effect; the situation is much worse than taking both positive and negative power from one of the three phases.

To cope with this adverse effect together with a voltage stabiliser both on the grid side and the train side, additional equipment called a railway static power conditioner (RPC) was introduced where it was thought necessary. An RPC can transfer active power from one side to the other and absorb necessary reactive power on each side independently (Ishikawa et al., 2015).

From a purely technical point, an RPC can be seen as sometimes necessary but from a totally economical design of the whole system, it is doubtful whether or not it is justifiable.

\subsubsection{Result of light-weight design of cars}

Know-how in constructing light-weight cars is by far the most advanced in Japan mainly because of the following three factors: (1) weak roadbed and infrastructures, (2) many privately owned train operators and car manufacturers, and (3) not too much buffer strength required as is necessary for heavy freight trains. After World War II passenger traffic demand expanded very rapidly between big cities and their suburbs, and the majority of this demand was carried on the suburban lines of the JPRs. Thus, light-weight and high performance EMUs were developed and manufactured from the early 1950s by JPRs which are the origin of the Shinkansen basic 
vehicle, with the other origin being $\mathrm{AC}$ electrification developed by the JNR. Some of the European car manufacturers think Japan's trainsets of small mass means there is not enough strength in a crash and some others think there is not enough rigidity against vibration. The former criticism has been proven wrong on various occasions: one of the typical cases is the Wenzhou collision on 2011-07-23. In this case a light-weight aluminium bodied CRH2 hit a comparatively heavy stainless steel bodied CRH1 and damage was much greater to the CRH1. The latter criticism is half true and half incorrect; it is a matter of the design's balance between riding comfort and energy saving. The mass per axle of less than $12 t$ of the E2 of the Tohoku Shinkansen, the origin of the CRH2, is the result of Japanese balance (Yang, 2012) and the roughly $15 \mathrm{t}$ of the CRH380A is the result of Chinese balance (Yang, 2015).

\subsubsection{Cab signal ATC}

Although there had been some cab signal systems in smaller urban railways, automatic train control (ATC) using a cab signal adopted by a major railway was a world first for the Shinkansen (Kotsu Kyoryoku Kai Foundation, 2015) and since its inauguration more than half a century has passed but still it is not perfect nor is there a final version of such a system. Japan's ATC is not intended for driverless operation but the braking operation is almost automatic with manual operation left for final stopping at a designated position at a train speed of below $30 \mathrm{~km} / \mathrm{h}$. The French TGV has a different philosophy; an automatic train protection (ATP) system should help the driver's operation by showing a forthcoming situation and only if the driver fails to react safely does the ATP system intervene. German philosophy is a little different to that of France but does not differ that much.

China has introduced several signalling systems from Europe and Japan and at the moment several systems are coexisting on the same track according to the several different trainsets. Coexistence of several signalling systems on the same track is not desirable from the standpoints of drivers' confusion, more maintenance work, and possible interference between the systems.

To solve this problem in the future, there will be much potential for solutions such as sorting the sys- tems into categories by area, line groups, speed range, or climate conditions, etc. The process and results of the Chinese solution will be paid strong attention to by the developed countries, none of which has had such a need as yet.

\subsubsection{Poor tracks and infrastructure in Japan}

The Shinkansen's weak points are often seen in the infrastructure; too little spacing between adjacent lines of $4.2 \mathrm{~m}$ (in the case of the Tokaido Shinkansen) or $4.3 \mathrm{~m}$ (Sanyo Shinkansen and all thereafter), a small cross section in double track tunnels of about $64 \mathrm{~m}^{2}$, a non-reversible signalling system, unique in the world, and a speed restriction of $70 \mathrm{~km} / \mathrm{h}$ at turnouts into and out of stopping stations. The poor infrastructure was justifiable for the Tokaido Shinkansen because it was the pioneer, who cannot learn from others, and because of the fact that Japan was not economically strong enough at the start of the construction in 1959. After minimal improvement of the Sanyo Shinkansen, further improvements in line with world standards have not been realised.

In contrast to this, China can choose from many products around the world and a traditionally strong infrastructure for heavy load has been in due course further improved for the HSR. Some Japanese infrastructure specialists say that poor turnouts from the viewpoint of restricted speed should be justified to maintain necessary reliability by prohibiting two or more shifting motors, which is thought the main reason of turnout troubles.

\section{Other developed countries' HSR technol- ogies (Akiyama, 2014)}

\subsection{Britain}

British Rail was the first railway to realise $200 \mathrm{~km} / \mathrm{h}$ operation successfully in 1976 . Although the success of the High Speed Train (HST) had greatly surprised Japanese traction engineers, who were confident of the need to have many driving axles to cope with the adhesion limit, the influences to Japan and many other countries were neglected or not strong because the HST was for non-electrified lines. The HST technology was exported only to the XPT in Australia; all other important HSRs have been electrified. 


\subsection{France and Germany}

After experimental introduction of locomotive hauled trains with $200 \mathrm{~km} / \mathrm{h}$ operation, with just a few trains on the same line, substantial HSR started in France in 1981 and in Germany in 1991 using a fixed formation concentrated traction system with locomotives at both ends, as the French TGV and the German ICE-1, respectively. The French TGV was built with much technology learned from the Japanese Shinkansen leading to a much improved HS system in French eyes. This success, together with a very high speed record established of $380 \mathrm{~km} / \mathrm{h}$ before regular services started, caused much attention in Japan, especially relating to current collection, which was one of the major sources of technical troubles in Japan. French railway specialists learned about poor Japanese current collection and moved to realise the use of a gas turbine, which can avoid current collection itself, but the world oil crisis brought the French back to electric power again. The TGV used only one pantograph over the rear locomotive to avoid troublesome problems of current collection at high speed, using over-the-roof high tension cables to feed current to the front locomotive. Japan in turn learnt from this but by using the same method with improvement; after careful tests of the numbers and positions of pantographs, electrically connected as the French ones. It was decided that the best position was not at the front or back of the train, where there is a whirling airflow, but at a rectified airflow position, and the best number of raised pantographs was two, almost always electrically connected even if one of the two jumped from the catenary. The same collection system cannot be adopted in Europe because of feeding sections and European rules prohibits the use of two or more interconnected pantographs.

\subsection{French vs. Japanese technologies}

French technologies were very different to Japanese ones. This was natural because the French had learnt from the experiences in Japan so there were many ways in which the French were superior to the Japanese such as the following:

Current collection: Many equally spaced individual pantographs vs. rear pantograph feeding its own locomotive and feeding the front traction unit with over-the-roof cable.

ATP: As described above, much more freedom given to the driver. For example, under the French nominal maximum speed limit of $260 \mathrm{~km} / \mathrm{h}$ in 1981 actual speed could be raised as high as to $285 \mathrm{~km} / \mathrm{h}$.

Train length: An allowed maximum of $300 \mathrm{~m}$, twelve $25 \mathrm{~m}$ long car fixed formation in 1964 or $400 \mathrm{~m}$ with a sixteen $25 \mathrm{~m}$ long car formation after 1970 in Japan or a half the maximum length formation of $200 \mathrm{~m}$ with a dual formation train as required (i.e., two $200 \mathrm{~m}$ long trainsets coupled together).

Adaptation to different demands in the train scheduling: The Japanese fixed pattern scheduling for the heaviest demand with surplus trains cancelled at lighter demand day and/or time vs. the French basic train scheduling for the minimum demand period with increased formation, i.e., dual trainsets coupled, and/or additional trains running before the advertised train. The decision of the operation scheduling was made about one month prior to actual operation in order to sell reserved seat tickets in Japan vs. up to about two days before travel according to the data of the sold tickets in France.

Among the different methods adopted by the French TGV, which were thought to be improvements by French railways, the following examples were thought not to be improvements by the Japanese:

Concentrated traction system: Less maintenance work required for a smaller number of higher power traction motors vs. more maintenance work required for many unmotored axles. In Japanese practical operations, increased maintenance work due to brake friction should substantially be avoided as is the additional mass and the possibility of fire.

Articulated configuration: No noisy bogies under passengers' feet and a smaller total mass vs. a smaller number but bigger axle load. In Japan, where track is weaker than in France, the priority is less maximum axle load.

Air suspension: The French explained that compared with commuter trains in which ratio of fully loaded vs. tare weights is big, the TGV does not require variable parameter suspension because the ratio is small.

\subsection{French vs. Japanese technologies in recent years}

Thirty-five years have passed since the TGV was first introduced in 1981. Most of the above mentioned differences have been judged by railway engineers worldwide. 
Current collection was once one of the severest problems of the Shinkansen; the TGV escaped from occasional troubles of current collection but later Japanese engineers could make further improvements, i.e., two parallel pantograph current collection system as described above.

ATP: The basic principles are still different from each other but the Japanese ATC have been improved so that riding comfort and punctual operation are realisable by both well trained and experienced French drivers and by all Japanese drivers.

Trainset length: The Tokaido Shinkansen is very special Shinkansen where the maximum transportation capacity is still not enough to meet the maximum traffic demand. For this reason JR Central, the operator of the Tokaido Shinkansen, does not wish to construct other than 16 car formations nor improve the amenities with less passenger capacity. But all other operators, JR East, the operator of Tohoku, Joetsu, and Hokuriku Shinkansen, JR West, the operator of the Sanyo Shinkansen and part of the Hokuriku Shinkansen, and JR Kyushu, the operator of the Kyushu Shinkansen, have different formations adaptable to different demands. The practice of half the maximum length formation with dual trainset coupled together as required is not widely adopted nowadays in Japan because of possible difficulty in evacuation in case of fire; in Japan escape from fire is thought necessary in both directions, forward and back. In order to realise this passengers must be able to walk through coupled trainsets; but to realise gangways between highly streamlined front ends is not practical on the Shinkansen. The Chinese practice of building both an 8 car formation and a 16 car formation as seen with the CRH380A and CRH380AL respectively seems to be learnt from original TGV's practice. JR West had once the same practice but in recent years two 8 car formations coupled together are no longer used.

Distributed traction: When DC traction motors were used, there was keen discussion between distributed vs. concentrated traction systems, but once $\mathrm{AC}$ traction motors, which are much lighter and require almost no maintenance work, were used everybody, except some of the French, was confident that distributed traction is much superior.

Air suspension: The TGV also introduced air suspension after realising the practical, not theoretical, superiority of air suspension for riding comfort.

Articulation: The Super Express (SE) trainset of OER, made in 1957, which provided many technical ideas and parts and practice to the Shinkansen's Series 0 trainset, was also of articulated configuration. JNR and JR East compared and sometimes built test cars with partially articulated trainsets and the results were not substantially superior nor inferior.

\section{Technologies of Chinese origin}

Introduction of distributed traction only: Apparently it is the same as in Japan but the reason was completely different. Japan introduced the system as the only practical solution for realising high speed operation, which was denied by the British HST in 1976, the French TGV in 1981, and the German ICE-1 in 1991. Japan could not persuade European railway engineers of the superiority of distributed traction systems until the 1990s when traction motors changed from DC motors, with maintenance required commutators, to AC motors with much less mass and no maintenance required. The Chinese decision, made in 2003, was thought wise enough because at that time not a few people were confident that the TGV was the world's best. This decision was supposed to be made based on experiences prior to 2003, when developments were made without license, and by discerning leaders who could evaluate many papers including the author's (Sone, 1994).

Coexistence of several different systems: This is because of the introduction of both Japanese and European practices. This has two effects, both favorable and unfavorable: The former which is favorable is to be able to judge from Chinese experience and the latter, unfavorable, is that the system is complicated and expensive, and sometimes difficult to maintain safety because of interference between the systems. Among many subsystems power feeding/ current collection and signalling system are important. The Japanese practice of power feeding/current collection is superior, with practically no interruption of power which enables continuous powering and regenerative braking beyond different phase areas and also taking auxiliary power directly from a main transformer, not through a bulky, costly, and heavy battery assisted AC-DC-AC converter, which is 
necessary with the $16.7 \mathrm{~Hz}$ catenary but not for 50 or $60 \mathrm{~Hz}$ catenary. Systems should be in multiple both on board and/or at the wayside if using trains with different signalling systems on one line or using the same trainset to run through to different signalling sections. In addition to costly construction, different systems sometimes interfere each other; preliminary elimination of the interference is almost impossible because the designer of system A does not know in detail about system $B$, and vice versa.

In near future China must conquer this problem either by unification or separation as far as possible: Either way has merit and demerit; nationwide unification tends to stop further improvement and separation tends to restrict necessary through operation or joint operation.

Chinese origins in the narrower sense: The fluid dynamic design of really HS trainset is thought to be one of the typical examples of this category (Fig. 4). The world's first HSR developed in Japan used tunnels of too small a diameter and too small distance between adjacent tracks. To cope with these poor conditions Japanese HS trainsets are very long with strange front shape (Oguri, 2015) (Fig. 5).

To contribute worldwide it is necessary for Chinese engineers to show an optimum, or nearly optimum, set of construction parameters as a function of the required maximum speed. Although the basic size of an HS trainset with $3.4 \mathrm{~m}$ wide and with $1.3 \mathrm{~m}$ floor height is not the solution to optimisation, it is common in the Japanese Shinkansen because of historical links between Japan and China. In other than Asian countries, traffic demand is not as high as in China or in Japan. These countries may require the optimum size as well as the number of cars in the formation.

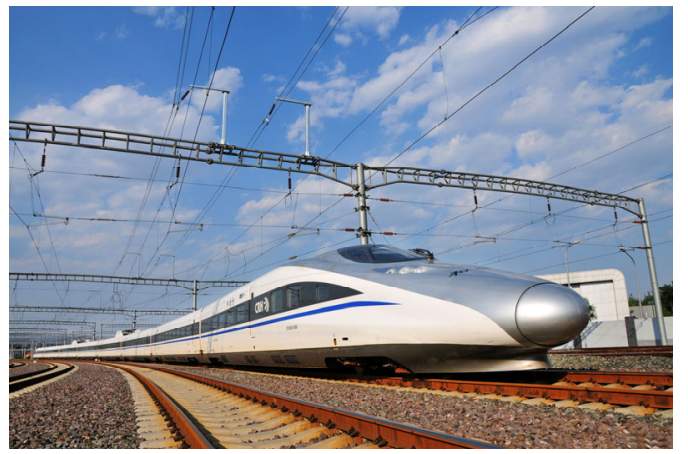

Fig. 4 CRH380A of Chinese Railways; based on Series 500 (front shape), E2 (traction system), and ICE-3 (front cabin design) totally improved by Chinese Railway designers

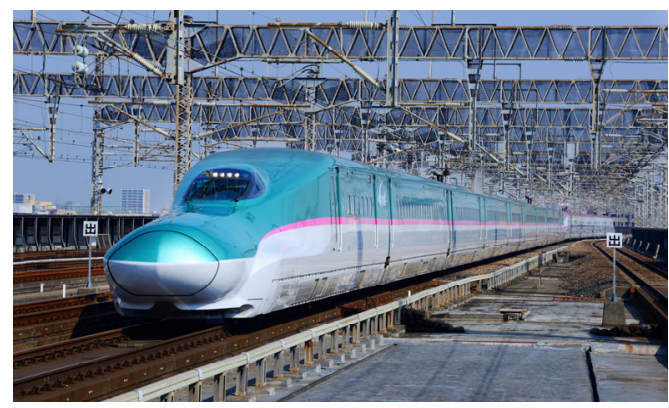

Fig. 5 Series E5 of East Japan Railways; Japan's highest speed operation at $320 \mathrm{~km} / \mathrm{h}$ on $4000 \mathrm{~m}$ radius curve assisted by body inclination control realized together with E6, seen at the rear of the photo

\section{Further discussion on technologies of Japan and China}

\subsection{Optimum motored to non-motored cars (MT) ratio and brake system design}

Japan has established the optimum design of motored cars in a fixed formation; if the formation is long enough such as 10 to 16 cars, all intermediate cars should be motored with the end cars non-motored. This is sometimes thought to provide surplus power and be too expensive but it is not so as described above. This means that even if surplus power is used only in braking, this is better than creating friction or any other types of kinetic energy to heat conversion brakes. It is very easy to use that installed surplus power with a reduced current so that there is not too much burden on the substation with a much reduced probability of wheel slip on acceleration.

For a short formation such as 6 or 8 cars, on a steep gradient section in some restricted situations such as a one traction unit cut-off, all axles should be motored with reduced traction effort in order not to create wheel slip, which can cause considerable errors in train speed and position in the front car. Also, special care should be taken not to cause the EMC problem as described in Section 3.2.2.

Contrary to Japanese practice, the German ICE-3, which was changed from ICE-1 and ICE-2 concentrated trainsets in order to meet the French axle load limit of $17 \mathrm{t}$ on the HS line, the LGV, has the formation of a driving motor and intermediate motors and trailers based on European locomotive technology. To develop CRH380B and CRH380BL Chinese HS 
engineers met some EMC problems due to emissions from the front motored car.

\subsection{Safety and reliable design and operation}

From the HS trainset design point of view, the most important factor is a safe, reliable, and high performance braking system (Kumagai, 2015). Although the final braking performance must be guaranteed by mechanical braking, taking multiple failures of electric systems into consideration, service braking as well as emergency braking should be dependent on electric braking in regenerative mode that produces no substantial heat. If some of the electrical subsystems are not reliable, such as interruption of supply for a considerably long time and/or wide area near the boundary of feeding areas, electric braking should be assisted by rheostatic braking as well, which produces substantial heat.

From the train operation's point of view, Japan's practice has been to build enough margin in the following areas of running time, adhesion, rise in temperature, train headway, supply voltage fluctuation, etc. What can be seen as too much surplus power and safety, such as in the 14M2T formation rather than the $12 \mathrm{M} 4 \mathrm{~T}$ trainsets, compared with Europeans the Japanese engineers are confident they can use a more reliable and safe operation without almost any negative effects by taking surplus current from substations; the squeezing of catenary current is very easy to achieve. Thus, when 1 unit (2M) out of the total 7 units is cut-off, the remaining 6 units can operate the train in normal mode, rather than squeezed mode.

\subsection{Design of automatic train protection (ATP)}

The design philosophy of the Shinkansen and the TGV has been different from each other with respect to the crew's role. In earlier years the TGV had better riding comfort due to deceleration, energy consumption, and in some cases average train speed. The Shinkansen's ATP, called ATC, has by several steps progressed to be today's digital ATC with continuous, not stepwise, braking dependable on the trainset's performance. But the author and some other railway engineers do not think it is the final version of such a protection system. The reason is as follows: As a protection device, applicable braking performance should be very low because even in the worst conditions, such as deep snow on the running rails, the train must be protected from collision, and in normal con- ditions the running time with manual driving is apparently shorter than when ATC is in operation. Actually on a snowy day in February 2014 a Toyoko Line's train using high performance continually controlled ATC, using the same philosophy with a different apparatus in detail from the Shinkansen's ATC, collided with the preceding train.

\section{Peculiarity of Japanese and Chinese railways}

Among many countries which have HSRs, Japan alone has almost no medium speed railways: between the Shinkansen, whose network of $2760 \mathrm{~km}$ with $260 \mathrm{~km} / \mathrm{h}$ or higher top speeds, and conventional lines of many operators totaling $24900 \mathrm{~km}$ whose maximum speeds do not exceed $130 \mathrm{~km} / \mathrm{h}$, only $70 \mathrm{~km}$ of lines operated by two companies have maximum speeds of between $130 \mathrm{~km} / \mathrm{h}$ and $260 \mathrm{~km} / \mathrm{h}$. One is the $160 \mathrm{~km} / \mathrm{h}$ Keisei Electric Railway and the other the $140 \mathrm{~km} / \mathrm{h}$ Seikan underground tunnel section between Honshu and Hokkaido of JR Hokkaido.

One of the most important social roles of Japan's railways is the suburban commuter traffic. Almost all of the commuter traffic inside the Tokyo metropolitan area, in about a $50 \mathrm{~km}$ radius and with a total population of around 26 million, is made by rail traffic sometimes combined with transport such as bus, bicycle or private car between home and the train station, by kiss and ride, not park \& ride mode. Tokyo's high density of population and efficient economic operation is kept moving thanks to this high-density rail traffic.

On the contrary, China has many medium speed railways but no efficient suburban railways. This is very strange if seen from the outside because both countries have many big cities, suitable for connection by railways either by HSR or by medium speed railways and some big cities like Beijing, Shanghai, and Chongqing have a big population in suburban areas that could be connected by efficient commuter railways. Some routes of railways in Chinese urban areas are provided by underground railways but actually in suburban areas most are elevated lines, which are independent from national railway network and not at all efficient from the standpoint of positionings of stations, spacing between stops and also for train scheduling patterns. Among the world's big 
cities the S-Bahn networks, urban and suburban railways, in Germany, Austria and German speaking Swiss areas, and the RER, a similar in French speaking area, are better than Chinese urban networks but inferior to the Japanese urban railways operated jointly by JPRs and JRs as well as local government railways.

\section{Important relationship to be kept between Japanese and Chinese HSRs}

As analysis was made in the previous sections showing that under similar social conditions and economic activities and based on modern railway technologies, the present status of HSRs, medium speed lines and suburban lines are too different from each other.

In the HSRs area, if we combine Japanese experience and the related know-how with highly reliable and safe components and Chinese efficient construction and manufacturing ability and highly progressive development, the results will contribute much to HSRs across the world (Zhang, 2009b).

No existing medium speed lines in Japan can hardly be justified socially. The so-called Yamagataand Akita-Shinkansen whose trainsets can run very fast on the Shinkansen tracks are only allowed to travel at up to $130 \mathrm{~km} / \mathrm{h}$ on conventional lines, converted from narrow gauge to standard gauge, because of safety at level crossing and for some other technical reasons. Practical know-how established in China will contribute to Japan upgrading the required conventional lines into medium speed railways.

Chinese suburban railways operated by local governments are different from the Chinese national network operator's lines in many ways. In Japan, after 1960 through operations in the Greater Tokyo area started between private railways and both local government railways including underground lines and national railways (the then JNR) by mutual discussion and the making of a through operations agreement. This was a very big success and the private railways' know-how about train operations has been gradually prevailing in Japan's conurbations. Important points relating this know-how include constructing many stations that are accessible on foot, and how to combine fast, limited stop, and slow trains, stopping at every station, and how to organise cross-platform transfer at major stations. If this is adopted in China the travelling time between home and the office can be dramatically shortened, taking access times into consideration.

\section{Conclusions}

Both countries, Japan and China, have their good points and weak points. In such a situation, to combine the good points, one country with those of the other will create a big profit for the railway industry and passengers in both countries in the following area: HSR, medium speed lines, and suburban lines. If the best combination in these important areas is realised, the de facto standard in the two countries can contribute to the rest of the world's passenger rail services.

\section{References}

Akiyama, Y., 2014. High speed rail worldwide-past and future. Special Issue 50 Years of High-Speed Railways. JRTR, 64:36-47.

Ehara, G., 2015. History of the Sanyo Shinkansen and the opening of the Hokuriku Shinkansen. Japanese Railway Engineering, 55(2):18-27.

Fukunaga, H., 2015. Technology and outlook for the Kyushu Shinkansen which has been in service for 10 years. Japanese Railway Engineering, 55(2):39-43.

Ishikawa, S., Ito, M., Inoue, Y., et al., 2015. The 50 year history of the Tokaido Shinkansen. Japanese Railway Engineering, 55(2):9-17.

Kotsu Kyoryoku Kai Foundation, 2015. 50 Years of the Shinkansen. Transportation News Co., Japan (in Japanese).

Kumagai, N., 2015. Creation of value using Shinkansen technology - strategies for improved safety and speed. Japanese Railway Engineering, 55(2):5-8.

Oguri, A., 2015. Commercial operation at $320 \mathrm{~km} / \mathrm{h}$ of the East Japan Railway Company's Shinkansen and transition of technology. Japanese Railway Engineering, 55(2):28-38.

Smith, R.A., 2014. The Shinkansen-world leading highspeed railway system. $J R T R$, 64:6-17.

Sone, S., 1994. Distributed versus concentrated traction systems - which can better meet the needs of customers and operators? World Congress on Railway Research, Paris, 1:239-244.

Sone, S., 2014. Technological History of Shinkansen for 50 Years-Progress and Future of High-speed Railways. Kodansha Blue Backs Series B1863 (in Japanese).

Study Group of High-speed Railways (Ed.), 2003. Shinkansen —all about High-speed Railway Technologies. Sankaido, Oct. (in Japanese).

Takai, H., 2015. Historical tracing of research and development on the Shinkansen. Japanese Railway Engineering, 
55(2):49-52.

Yang, Z.P., 2012. All about Shinkansen—Japanese High-speed Rail Technology, 2nd Edition. China Railway Publishing House, China (in Chinese).

Yang, Z.P., 2015. Technical Outline of High-speed Railways. Tsinghua University Press, Beijing, China (in Chinese).

Zhang, S.G., 2009a. Study on Design Methods of High-speed Trains. China Railway Publishing House, China (in Chinese).

Zhang, S.G., 2009b. Study on Improving Beijing to Shanghai High-speed Railway System. China Railway Publishing House (in Chinese).

\section{中文概要}

题 目: 中国高铁与日本新干线技术比较

概 要: 本文主要从技术的角度对日本和中国的高速铁路 技术进行比较。首先介绍日中两国高速铁路的发 展简史, 并用数字说明两国在高速铁路运营里 程、旅客发送量和高速列车数量等方面的现状。 其次, 比较分析日中两国高速铁路在高速列车设 计理念、自动过电分相、电磁兼容、再生制动列
车导入后的相平衡措施和列车轻量化等技术方 面上的差异, 并侧重阐述日本在轻量化和编组动 拖比优化等方面取得的成功经验。其三, 介绍英 国、法国和德国的高速铁路技术, 并以日本为比 较对象, 从受流、列车超速防护、列车长度、运 行图、动力方式和转向架结构等方面说明法国高 速铁路技术的特点。其四, 分析中日两国高速列 车采用相同的动力分散方式背后的不同原因以 及中国引进日欧技术导致多种技术并存的优点 和缺点。其五, 提出中日两国今后应重点讨论的 几个技术问题, 如编组动拖比优化、制动系统设 计、安全和可靠性设计以及车载列控系统设计 等。最后, 从日中两国中速铁路和市郊铁路存在 明显差异的角度, 分析日中两国铁路的特殊性, 提出两国在高速铁路、中速铁路以及城市轨道交 通领域相互取长补短的具体方法。

关键词: 高速铁路; 中速铁路; 城市轨道交通; 动力分散; 动力集中; 编组动拖比; 电流集中; 电磁兼容性 问题; 安全性和可靠性; 协调性

(感谢北京交通大学电气工程学院杨中平教授提供中文 概要) 